\title{
Diagnosis and management of a mediastinal ectopic thyroid laying on the right bronchus: case report and review of literature
}

\author{
Alessio Metere $^{1 *}\left(\mathbb{D}\right.$, Tiziano De Giacomo ${ }^{2}$, Massimo Vergine ${ }^{1}$, Marco Biffoni ${ }^{1}$ and Laura Giacomelli ${ }^{1}$
}

\begin{abstract}
Background: The mediastinal ectopic thyroid is very rare, accounting for less than $1 \%$ of all cases of ectopic thyroid tissue. The differential diagnoses with other diseases such as lymphomas, thymic tumors and dermoid cysts is mandatory, in fact each one, needs different management and treatment.

Case presentation: Here, we discuss a rare case of mediastinal ectopic thyroid presenting with a paratracheal mass laying on the right bronchus without symptoms. A 63-year-old male presented with an abnormal well-defined mass along the right paratracheal side, detected by chest $x$-ray. The $C T$ scan confirmed the presence of a $6 \times 8 \mathrm{~cm}$ heterogeneously enhanced mass, located behind the superior vena cava and left brachiocephalic artery, reaching azygos vein and right bronchus, without a mass effect. Taking into account the clinical importance of a mediastinal mass, we removed it surgically, through a double surgical approach consisting in a classical transverse cervicotomy for the left thyroid lobe, followed then by a longitudinal sternal splitting to remove the mediastinal mass and complete the thyroidectomy.

Conclusions: In case of mediastinal masses, the surgical excision is recommended, presenting the double advantage to clarify the diagnosis and to treat the pathology. As demonstrated in this case, a mediastinal ectopic thyroid should be taken into account in the differential diagnosis, considering its clinical importance.
\end{abstract}

Keywords: Ectopic thyroid, Mediastinal thyroid, Mediastinal mass

\section{Background}

Thyroid gland is usually in the neck, anterolaterally from the second to fourth tracheal cartilages, less frequently could be found in other sites and it is called Ectopic Thyroid Tissue (ETT). The wall of the thyroglossal duct cyst is a common site for ETT, even if, other rare sites, such as retroperitoneum, adrenal gland, skull and lung have also been described [1-4]. The embryologic development gives reason to the main localization of ETT. The lingual thyroid tissue (at the base or below the tongue), accounts for $90 \%$ of these abnormalities followed by intratracheal ETT, while the mediastinal ETT is very

\footnotetext{
* Correspondence: alessio.metere@gmail.com

${ }^{1}$ Department of Surgical Sciences, Umberto I Hospital, "Sapienza" University

of Rome, viale Regina Elena 324, Rome 00161, Italy

Full list of author information is available at the end of the article
}

rare, accounting for less than $1 \%$ of all cases [5]. The differential diagnosis of anterior mediastinal mass is very important and includes some pathologies such as lymphomas, thymic tumors, dermoid cysts and mediastinal ectopic thyroid which need different management and treatment. Here, we discuss a rare case of mediastinal ectopic thyroid presenting with a paratracheal mass on the right bronchus, without any symptoms.

\section{Case presentation}

A 63-year-old male presented with an abnormal welldefined mass along the right paratracheal side, detected by a chest $\mathrm{x}$ ray performed 2 weeks earlier, to exclude a diagnosis of pneumonia. We admitted the patient to our hospital to take the medical history, perform blood exams and contrast-enhanced CT scan, to better 


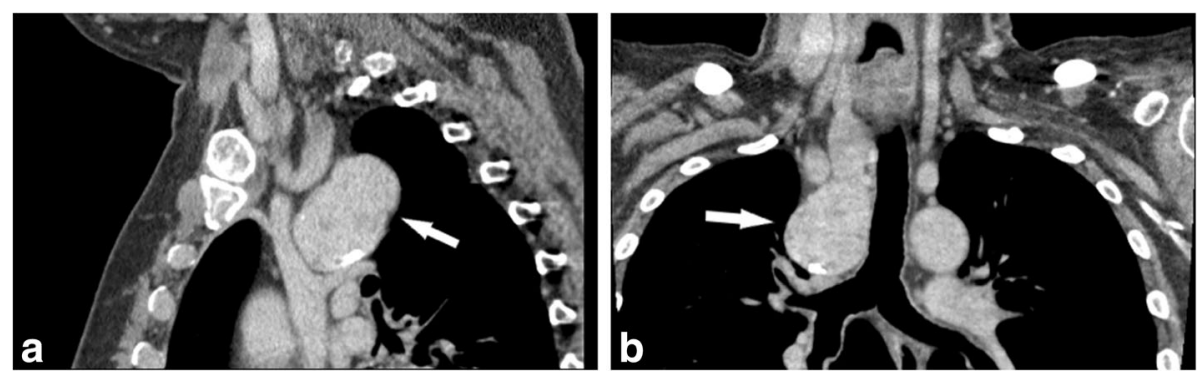

Fig. 1 a Lateral view and $\mathbf{b}$ Frontal view of enhanced-CT scan of neck and chest showing the mediastinal mass (white arrow) and the mediastinal structures around

characterize the lesion. The CT scan of neck and chest confirmed the presence of a $6 \times 8 \mathrm{~cm}$ heterogeneously enhanced mass in the right paratracheal area, characterized by some signs of necrosis inside. In particular, the mass was located behind the superior vena cava and left brachiocephalic artery, along the right side of the trachea, until reaching the azygos vein and the right bronchus, without any sign of compression regarding the organs around (Fig. 1). Interestingly, the contrastenhanced CT scan showed a thin strip of tissue that linked the left thyroid lobe to chest mass, consisting with the hypothesis of a right "mediastinal thyroid lobe" (Fig. 2). No family history of thyroid disorder nor clinical signs of thyroid disease were detected. The results of his laboratory tests were all within normal limits and included a TSH level of $1.46 \mu \mathrm{UI} / \mathrm{L}$ (normal range, 0.40 to 4.00 ), free T3 of $1280 \mathrm{pmol} / \mathrm{L}$ (normal range, 600 to 1950), and free $\mathrm{T} 4$ of $12.3 \mathrm{pmol} / \mathrm{L}$ (normal range, 7.8 to 19.4 ). The serum levels of thyroid autoantibodies were also within normal ranges; $\mathrm{Ab}$ anti-TPO was $<25 \mathrm{U} / \mathrm{mL}$ (normal range, $<100$ ) and $\mathrm{Ab}$ anti-TG was $<25 \mathrm{U} / \mathrm{mL}$ (normal range, $<100$ ). As previously described, the differential diagnosis of anterior mediastinal mass is very important and includes some pathologies which need different management and treatment. We decided that the best treatment was to remove it surgically. We planned a double surgical approach consisting in a classical transverse cervicotomy to perform the left thyroidectomy followed by a longitudinal sternal splitting to remove the mediastinal mass and complete the thyroidectomy (Fig. 3). We preferred to perform a mini invasive surgery for the chest, through an upper partial sternal split, extended to the 4th intercostal spaces. Briefly, the manubrium was completely divided and the sternotomy carried to the level of the fourth interspace. The subsequent divarication of the sternum cause a fracture

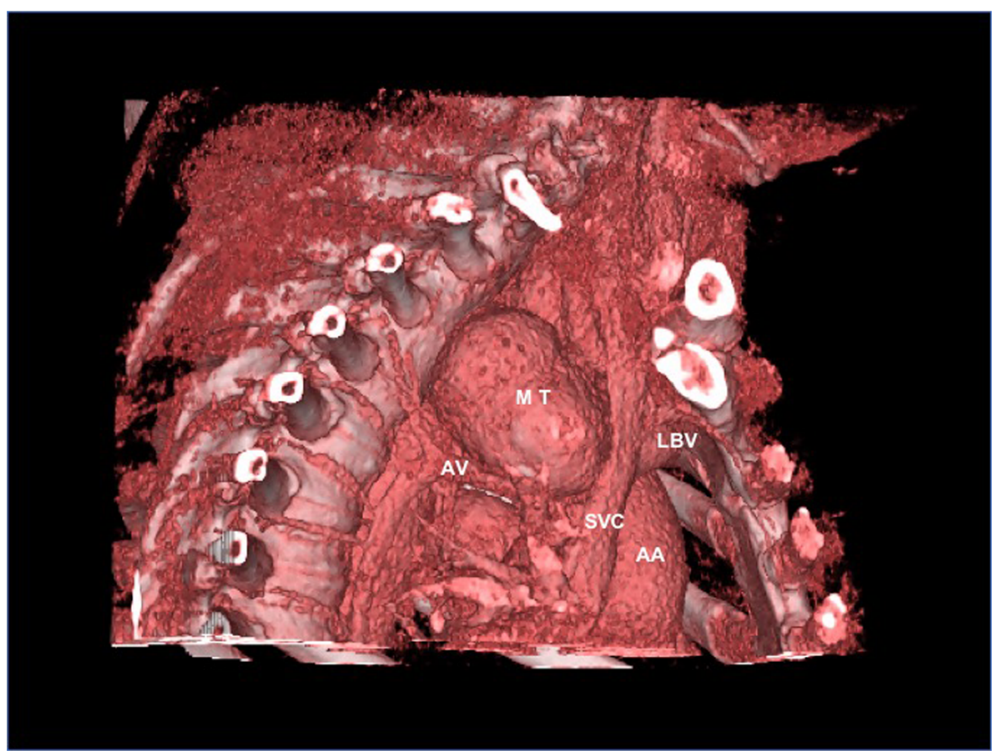

Fig. 2 Tridimensional contrast Enhanced-CT reconstruction (AV: azygos vein; MT: mediastinal mass; SVC: superior vena cava; AA: ascending aorta; LBV: left brachiocephalic vein) 

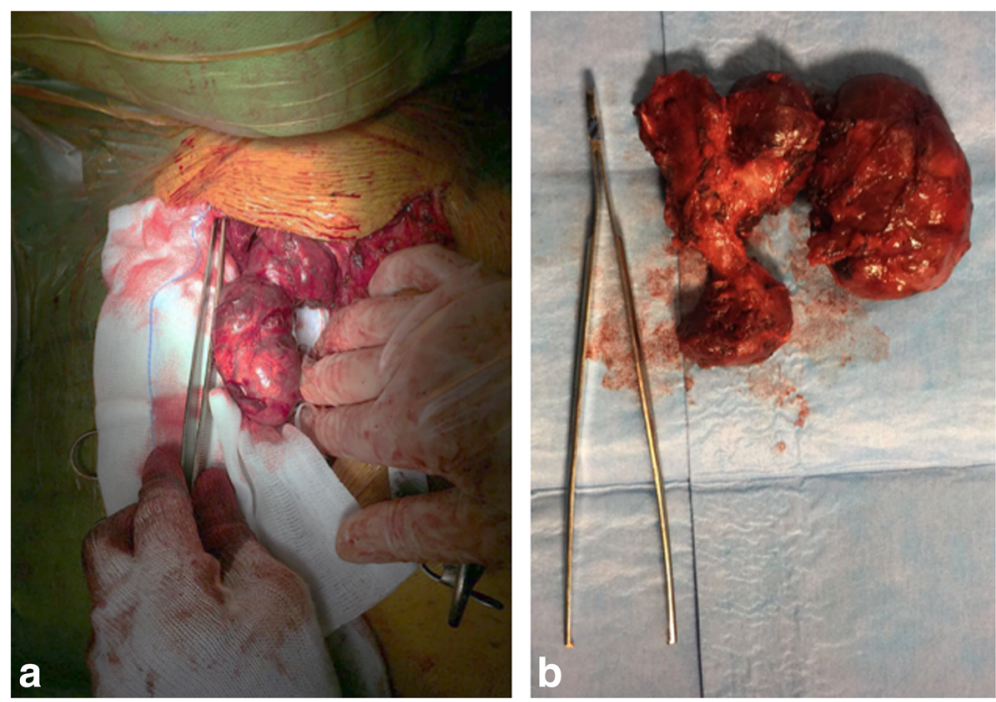

Fig. 3 a Intraoperative isolation of mediastinal thyroid through sternal splitting. $\mathbf{b}$ Cervical and mediastinal thyroid after excision

which then was later stabilized with sternal stitches. This technique was able to provide an effective surgical field, minimizing the surgical complication related to the total sternotomy.

The histological exam confirmed that the chest mass was thyroid tissue, no neoplastic cells were found but only the typical features of the multinodular goiter. No post-operative complications were observed, neither hypocalcemia nor nerves injuries, thus the patient was discharged on the sixth post-operative day.

\section{Discussion and conclusions}

As previously described, the wall of a thyroglossal duct cyst is the common site for ETT followed by others considered

Table 1 Literature Review Summary Table

\begin{tabular}{llll}
\hline Year Author & Country & Title & Conclusions \\
\hline 2016 Cao L, et al. [1] & China & $\begin{array}{l}\text { Clinical Characteristic and molecular } \\
\text { pathology of skull ectopic thyroid cancer }\end{array}$ & $\begin{array}{l}\text { The ETT was correlated with Akt/mTOR pathway high expression; } \\
\text { orthotopic thyroid was related with MAPK/BRAF/ERK signaling } \\
\text { pathway high expression; and the metastatic thyroid cancer was } \\
\end{array}$ \\
& & $\begin{array}{l}\text { related with NFkB/MMP9 high expression. } \\
\end{array}$
\end{tabular}
$2013 \mathrm{Ko} \mathrm{HH}$, et al. [2] Korea Ectopic intrapulmonary thyroid:

2013 Wang SC, et al. [3] Taiwan Ectopic Thyroid Tissue in the Adrenal Gland Mimicking a Pheochromocytoma

2017 Tamaki S, et al. [4] Japan Laparoscopic resection of retroperitoneal ectopic thyroid tissue

2003 Gamblin TC, et al. [5] USA Ectopic thyroid

2004 De Felice M, et al. [6] Italy

2013 Nettore IC, et al. [7]

Italy

Thyroid development and its disorders: genetics and molecular mechanisms

The molecular causes of thyroid dysgenesis: a systematic review

2010 Abu-Khudir R, et al. [8] Canada Transcriptome, methylome and genomic variations analysis of ectopic thyroid glands
In this case the patient was previously operated for thyroid cancer and later an ectopic intrapulmonary thyroid was discovered at the follow-up.

Ectopic thyroid tissue occurring in the adrenal gland is extremely rare. Tsujimura $t$ al. [11] reported the first case of ETTAG in 1996.2 Until now, there have been only 11 cases reported in the literature.

This case shows the unusual finding of ectopic thyroid tissue in the retroperitoneum and the usefulness of laparoscopy for resecting such masses.

Here is presented a case of ETT extended from the thoracic inlet inferiorly, anterior to the heart, with severe tracheal deviation to the patient's right.

Gene-targeting experiments have demonstrated that Foxe1 is required for thyroid migration and that mice homozygous for Foxe1 mutations show a sublingual thyroid.

Several mutations in genes playing a role during thyroid morphogenesis such as NKX2-1, PAX8, FOXE1, NKX2-5, TSHR, have been reported in ETT

This study analyzed gene expression, genome-wide methylation, and structural genome variations in normal versus ETT, demonstrating a differential gene expression in ETT. 
very rare. The most common and reasonable hypothesis to explain the presence of ectopic thyroid, takes into account some defects in the differentiation, migration or growth of thyroid tissue, happened during the embryological development. However, other interesting working hypothesis takes into account the role played by genetic expression in the understanding of molecular mechanisms regulating the size, shape, and position of thyroid [6]. In these cases, in fact, several mutations in genes playing a role during thyroid morphogenesis such as NKX2-1, PAX8, FOXE1, NKX2-5, TSHR, have been reported [7]. Abu-Khudir R. et al. analyzed gene expression, genome-wide methylation, and structural genome variations in normal versus ETT, demonstrating a differential gene expression in ETT [8]. Unfortunately is necessary a large cohort to reveal and confirm, definitively, the involvement of one or more genes as responsible for defective thyroid migration during embryogenesis. It is important to underline that the mediastinum contains several pluripotent cells, that justify the large variety of tumors, such as lymphomas, endocrine or neuroendocrine carcinomas, primary thymic carcinomas or mesenchymal tumors, that can be found in this anatomical district. Hodgkin lymphoma, large B cell lymphoma and lymphoblastic lymphoma are the most common mediastinal lymphomas, while thymic and neuroendocrine carcinomas are rarer but highly malignant. Moreover, lymphomas and neuroendocrine carcinomas are usually located in the anterior mediastinum while the neurogenic tumors are frequently found in the posterior side. The localization in the mediastinum of mesenchymal tumors is very rare and usually uneventfully [9] (see table 1 for literature review). Mediastinal goiter is usually asymptomatic and consequently is discovered incidentally, like in our case, until the structures in the chest remain uninvolved. On the contrary, the patients refer dyspnea, cough and a sensation of retrosternal mass, often in case of mediastinal thyroid carcinomas. It is possible to clarify the diagnosis using several approaches, such as fine needle aspiration (US or CT-guided) or endobronchial ultrasoundguided transbronchial needle aspiration [10]. The mentioned techniques help us obtain information about the nature of the mass, even if they do not usually influence the surgical procedure. We discussed about the opportunity to perform a biopsy before surgery, but we decided to avoid it because of the high risk of complications due to the several anatomical structures surrounding the mass. Moreover, considering the anatomical dislocation of the mass, from the neck to the right bronchus, the opportunity to obtain histological samples representative of the entire tissue would have been very rare. In fact, for mediastinal mass and in particular for mediastinal thyroid mass, surgery should be considered because of the high risk of compression of the surrounding mediastinal organs. In conclusion, according to our experience, the surgical excision of mediastinal ectopic thyroid is recommended to obtain, at the same time, the definitive diagnosis and treatment. Frequently, it represents the elective treatment in case of thyroid cancer or multinodular goiter, taking into account that both tend to increase their mass and compress the mediastinal structures around.

\section{Abbreviation \\ ETT: Ectopic thyroid tissue}

\section{Acknowledgements}

This work represents a phD research project of the Doctorate "Biotechnology in Clinical Medicine" of the "Sapienza", University of Rome. We are grateful to Prof. S. Filetti, prof. M. Arca and Piero Trapani for the helpful advice.

Funding

Not applicable.

Availability of data and materials

The data supporting the conclusions of this paper are included within the article.

Authors' contributions

AM described the case and drafted the manuscript. LG, TDG and AM performed surgery, MV and MB assisted with the manuscript preparation and collected references. All authors read and approved the final manuscript.

Ethics approval and consent to participate

All procedures performed in studies involving human participants were in accordance with the 1964 Helsinki declaration and its later amendments or comparable ethical standards and with the ethical standards of the ethics committee of the Sapienza University of Rome that approved the study (Id number: 40/70).

\section{Consent for publication}

Written informed consent was obtained from the participants for publication of this article and any accompanying tables/images. A copy of the written consent is available for review by the Editor of this journal.

\section{Competing interests}

The authors declare that they have no competing interests.

\section{Publisher's Note}

Springer Nature remains neutral with regard to jurisdictional claims in published maps and institutional affiliations.

\section{Author details}

'Department of Surgical Sciences, Umberto I Hospital, "Sapienza" University of Rome, viale Regina Elena 324, Rome 00161, Italy. 'General Surgery, Surgical Specialties and Organ Transplantation "Paride Stefanini", Umberto I Hospital, "Sapienza" University of Rome, viale Regina Elena 324, Rome 00161, Italy.

Received: 9 February 2018 Accepted: 28 March 2018

Published online: 04 April 2018

\section{References}

1. Cao L, Wang Z, Ma J, Chen J, Zhu H, Zhou X, Zhu Q, Dong J, Lan Q, Huang Q. Clinical characteristics and molecular pathology of skull ectopic thyroid cancer. Ann Transl Med. 2016;4(23):462.

2. Ko HH, Cho SW, Lee HS, Kim HS, Nam ES, Cho SJ. Ectopic intrapulmonary thyroid: a case report. Korean J Thorac Cardiovasc Surg. 2013;46(3):237-9.

3. Wang SC, Hung SW, Lee CH, Ho HC, Ou YC, Yang CK. Ectopic Thyroid Tissue in the Adrenal Gland Mimicking a Pheochromocytoma. J Endourol Case Rep. 2017:3(1):149-51.

4. Tamaki S, Miyakura Y, Someya S, Ishikawa H, Kakizawa N, Hasegawa F, Tanaka H, Kikugawa R, Tsujinaka S, Tanaka A, et al. Laparoscopic resection of retroperitoneal ectopic thyroid tissue. Asian J Endosc Surg. 2017;10(3):331-3. 
5. Gamblin TC, Jennings GR, Christie DB, Thompson WM, Dalton ML. Ectopic thyroid. Ann Thorac Surg. 2003;75(6):1952-3.

6. De Felice M, Di Lauro R. Thyroid development and its disorders: genetics and molecular mechanisms. Endocr Rev. 2004:25(5):722-46.

7. Nettore IC, Cacace V, De Fusco C, Colao A, Macchia PE. The molecular causes of thyroid dysgenesis: a systematic review. J Endocrinol Investig. 2013;36(8):654-64.

8. Abu-Khudir R, Paquette J, Lefort A, Libert F, Chanoine JP, Vassart G, Deladoëy J. Transcriptome, methylome and genomic variations analysis of ectopic thyroid glands. PLoS One. 2010;5(10):e13420.

9. Macchiarini P, Ostertag H. Uncommon primary mediastinal tumours. Lancet Oncol. 2004;5(2):107-18.

10. Ozturk A, Cicek T, Aktas Z, Demirag F, Yilmaz A. Mediastinal ectopic thyroid diagnosed by endobronchial ultrasound-guided transbronchial needle aspiration: Report of three cases. J Clin Ultrasound. 2017;00:1-3. https://doi. org/10.1002/jcu.22530.

11. Tsujimura A, Takaha M, Takayama H, Sugao H, Takeda M, Kurata A. Ectopic thyroid tissue in a cystic adrenal mass. Br J Urol. 1996;77(4):605-6.

Submit your next manuscript to BioMed Central and we will help you at every step:

- We accept pre-submission inquiries

- Our selector tool helps you to find the most relevant journal

- We provide round the clock customer support

- Convenient online submission

- Thorough peer review

- Inclusion in PubMed and all major indexing services

- Maximum visibility for your research

Submit your manuscript at www.biomedcentral.com/submit
Biomed Central 